The relationship of dispositional compassion with well-being : a study with a 15-year prospective follow-up

Saarinen, Aino I. L.

2020-11-01

Saarinen , A I L , Keltikangas-Jarvinen , L , Pulkki-Raback , L , Cloninger , C R , Elovainio , M , Lehtimaki , T , Raitakari , O \& Hintsanen , M 2020 , ' The relationship of dispositional compassion with well-being : a study with a 15-year prospective follow-up ', Journal of Positive Psychology , vol. 15 , no. 6 , pp. 806-820 . https://doi.org/10.1080/17439760.2019.1663251

http://hdl.handle.net/10138/320616

https://doi.org/10.1080/17439760.2019.1663251

unspecified

acceptedVersion

Downloaded from Helda, University of Helsinki institutional repository.

This is an electronic reprint of the original article.

This reprint may differ from the original in pagination and typographic detail.

Please cite the original version. 


\section{The relationship of dispositional compassion with well-being: a study with a 15-year prospective follow-up}

Running head: Compassion and well-being

Aino I. L. Saarinen ${ }^{1,2}$, Liisa Keltikangas-Järvinen ${ }^{2}$, Laura Pulkki-Råback ${ }^{2}$, Claude Robert Cloninger ${ }^{3}$, Marko Elovainio $^{2,4}$, Terho Lehtimäki ${ }^{5}$, Olli Raitakari ${ }^{6}$, Mirka Hintsanen ${ }^{1}$

${ }^{1}$ Research Unit of Psychology, University of Oulu, Finland

${ }^{2}$ Department of Psychology and Logopedics, Faculty of Medicine, University of Helsinki, Finland

${ }^{3}$ Department of Psychiatry, Washington University, St. Louis, United States

${ }^{4}$ National Institute for Health and Welfare, Helsinki, Finland

${ }^{5}$ Department of Clinical Chemistry, Fimlab Laboratories and Faculty of Medicine and Health Technology, Finnish Cardiovascular Research Center, Tampere University, Tampere, Finland

${ }^{6}$ Research Centre of Applied and Preventive Cardiovascular Medicine, University of Turku, Finland;

Department of Clinical Physiology and Nuclear Medicine, Turku University Hospital, Finland

*Corresponding author: Mirka Hintsanen. Research Unit of Psychology, University of Oulu, Oulu, Finland. P.O. Box 2000 (Yliopistokatu 9), 90014 University of Oulu, Oulu, Finland. Email: mirka.hintsanen@oulu.fi; gsm: +358 505695243 


\section{Abstract}

We investigated the associations of individual's compassion for others with his/her affective and cognitive well-being over a long-term follow-up. We used data from the prospective Young Finns Study $(N=1312-1699)$ between 1997-2012. High compassion was related to higher indicators of affective well-being: higher positive affect $(B=0.221, p<.001)$, lower negative affect $(B=-0.358$, $p<.001$ ), and total score of affective well-being (the relationship of positive versus negative affect) $(\mathrm{B}=0.345, p<.001)$. Moreover, high compassion was associated with higher indicators of cognitive well-being: higher social support $(\mathrm{B}=0.194, p<.001)$, life satisfaction $(\mathrm{B}=0.149, p<.001)$, subjective health $(\mathrm{B}=0.094, p<.001)$, optimism $(\mathrm{B}=0.307, p<.001)$, and total score of cognitive well-being $(\mathrm{B}=0.265, p<.001)$. Longitudinal analyses showed that high compassion predicted higher affective well-being over a 15-year follow-up $(\mathrm{B}=0.361, p<.001)$ and higher social support over a 10-year follow-up $(\mathrm{B}=0.230, p<.001)$. Finally, compassion was more likely to predict well-being $(\mathrm{B}=[-0.076$; 0.090]) than vice versa, even though the predictive relationships were rather modest by magnitude.

Keywords: Compassion; Personality; Well-being; Happiness; Longitudinal 


\section{Introduction}

The lifetime prevalence of mental disorders is approximately 30\% (Steel et al., 2014), but that does not mean that the rest of the population experiences subjective well-being. Indeed, less than $30 \%$ of the population is flourishing in most European countries (Huppert \& So, 2013) and only 17\% in the US (Keyes, 2002). Consequently, it has been concluded that well-being refers not only to the absence of psychiatric symptomatology, but psychological well-being represents a distinct dimension from illbeing (Ruini et al., 2003; Ryff et al., 2006, 2014). Subsequently, there has been a demand that more research should be directed to positive psychological factors that might promote well-being (Sin \& Lyubomirsky, 2009; Meyers et al., 2013).

Compassion is regarded as a core factor contributing to well-being in several theoretical models (see Duarte, 2014). By definition, compassion refers to a concern for other's suffering and a desire to alleviate it (Goetz et al., 2010). In the recent years, compassion training has been included in a variety of psychotherapeutic interventions, such as meditation and mindfulness programs (e.g. Hofmann et al., 2011; Kirby, 2017) and cognitive behavior therapy (e.g. Gilbert, 2010; Gilbert \& Procter, 2006). At the present, compassion-focused cognitive training and mindfulness-based cognitive practices can be considered as third wave cognitive behavior therapy approaches (e.g. Hunot et al., 2013). Evidence suggests that interventions including compassion training effectively promote subjective well-being (Kirby, 2017; Kirby et al., 2017b). However, since the follow-ups have been comparatively short-term (at most a few months), it remains to be investigated the effect of compassion is state-like or whether compassion might have a more stable effect on one's subjective well-being. Additionally, in the lack of long follow-ups, the predictive relationships of compassion and well-being have remained uncertain. This was the aim of the present study. 
Psychological well-being is a multidimensional concept that is commonly viewed from the perspectives of affective and cognitive dimensions (e.g. Diener et al., 2003; Jayawickreme et al., 2012; Waterman, 2008). Affective well-being refers to how positive feelings one has about the life; that is, the degree to which one experiences various positive affects (e.g. excitement, contentment, joy) versus negative affects (e.g. shame, nervousness) over time (Kahneman, 1999; Waterman, 2008). This affective well-being is often regarded as a golden standard of measuring human well-being (Kashdan, Biswas-Diener \& King, 2008). Instead, cognitive well-being refers to more reflective, evaluative, and rational views about how one's life is going, both in relation to one's intrinsic goals and to the interpersonal context (Diener et al., 2003; Jayawickreme et al., 2012). Typically, the degree of cognitive well-being is evaluated by characteristics such as life satisfaction, social connectedness with others, subjective experiences about physical health, and optimistic expectations of life (e.g. Diener et al., 2003; Ryff, 1989; Seligman, 2011; Maslow, 1971).

Overall, there is evidence that a range of factors correlate with better well-being, for example, high level of income, internal migration, aging-related changes, positive daily events, and favorable neighborhood qualities (Di Tella et al., 2010; Nowok et al., 2013; Sellström \& Bremberg, 2006; Steverink et al., 2001). Most of these factors, however, are relatively difficult to change without large-scale societal interventions and, hence, comparatively difficult to utilize when tailoring interventions to optimize one's well-being. Instead, there is accumulating evidence that compassion for others can be effectively cultivated with compassion interventions (Jazaieri et al., 2013; Kirby, 2017; Kirby et al., 2017b; Mongrain et al., 2011). Still, however, the relationship of compassion with wellbeing has remained mostly unexplored.

Cross-sectional studies in non-clinical populations have suggested that some compassionrelated concepts correlate with indicators of well-being. For example, there is evidence that kindness, altruism, cognitive and affective empathy, and prosociality are linked with higher life satisfaction, 
higher social connectedness, higher positive affect, and higher happiness (e.g. Post, 2005; Seppala et al., 2013; Thomas et al., 2007; Weinstein \& Ryan, 2010). Additionally, it has been shown that high self-compassion is related to better well-being (Barnard \& Curry, 2011), especially to better cognitive well-being (Zessin et al., 2015). However, the findings about self-compassion cannot be fully generalized to compassion for others since self-compassion seems not to even correlate with compassion for others in some studies (e.g. Neff \& Pommier, 2013).

Consequently, for compassion as such, the evidence is almost completely lacking. Overall, previous findings strongly suggest that compassion may likely have a more crucial role for well-being than other compassion-related concepts such as prosociality or empathy. For example, compassion is reported to be associated with well-being independently of helping behavior, whereas such an independent relation was not found between helping behavior and well-being (Steffen \& Masters, 2005). Additionally, contrary to compassion, empathy refers to the capacity to share both positive and negative affective states of others, so that in many cases empathy eventually results in emotional distress (Goetz et al., 2010; Singer \& Klimecki, 2014). Moreover, prosocial behavior differs from compassion since prosociality may not necessarily derive from compassionate motives (e.g. fear of negative evaluations, fear of rejection, desire for acceptance) (Catarino et al., 2014). Furthermore, there is evidence that excessive levels of empathy, altruistic concern, and altruistic behavior may be linked with psychiatric symptoms such as depression (e.g. Fujiwara, 2007; O’Connor et al., 2002; Schieman \& Turner, 2001), whereas high compassion is found protect against depression (e.g. Balsamo et al., 2013; Richter et al., 2000). Additionally, it has been demonstrated that practicing empathic resonance to human suffering increases negative affect because of increased stress levels, whereas practicing compassion decreases negative affect and increases positive affect (Klimecki et al., 2013). Finally, compassion also differs from positive affect since positive affect may not result from compassionate sources. In most extreme cases, even violent ideas may result in experiencing positive 
affect in some individuals (e.g. Međedović, 2017). Additionally, even though a correlation between positive affect and compassion has been obtained, positive affect is not a part of compassion. Instead, by definition compassion includes a concern for other's suffering (Goetz et al., 2013).

Despite compassion is suggested to have a particularly essential role for well-being, longitudinal research on this topic has still remained scarce. A few intervention studies have suggested that practicing compassion, kindness, or altruistic acts predicts higher well-being (Buchanan \& Bardi, 2010; Mongrain et al., 2011). The follow-up periods, however, have ranged from only 10 days up to 6 months. Subsequently, two reviews have concluded that the relationship of psychological traits with the course of well-being should be investigated over substantial periods of time (McNulty \& Fincham, 2012; Post, 2005).

In the absence of studies with long-term follow-ups, the direction of the association between compassion and well-being have remained unclear. That is, evidence is largely lacking about whether high well-being could increase dispositional compassion for others, or whether experiencing compassion for others could enhance one's well-being. On one hand, it has been suggested that certain level of well-being might be required before an individual is able to feel compassion for others. For example, it has been found that in circumstances characterized by high levels of stress, dissatisfaction, and negative affect, individuals are more prone to conduct bullying, direct aggression toward others, and even to commit violence in interpersonal relationships (e.g. Hauge et al., 2009; Hershcovis et al., 2007; Lewis \& Fremouw, 2001). Moreover, the emergence of a depressive disorder is linked to a decrease in compassion-related traits (Cusi et al., 2011).

On the other hand, there is evidence also for an opposite temporal direction, i.e. from higher compassion for others to a higher level of experienced well-being. For example, it has been found that compassion interventions are related to reductions in perceived stress (Judge et al., 2012; Lucre \& Corten, 2013). Stressful life events such as unemployment, divorce, or accidents, in turn, are 
shown to predict long-lasting reductions in subjective well-being in many cases (Lucas, 2007), especially in cognitive well-being (Luhmann et al., 2012). Moreover, it has been suggested that compassion interventions may alter the neural processing of affective stimuli in cortical and subcortical circuitries, such as amygdala, anterior insula, anterior cingulate, hypothalamus, mesencephalon, posteromedial cortices (Immordino-Yang et al., 2009; Lutz et al., 2008). Differences in the level of positive and negative affect, in turn, are known to be essential features of well-being (e.g. Waterman, 2008).

The present study aimed to investigate the association of dispositional compassion with well-being over a long-term follow-up and several assessment points. Specifically, the first aim was to investigate the cross-sectional associations of dispositional compassion with a variety of indicators for affective well-being (i.e. positive affect, negative affect) and cognitive well-being (i.e. life satisfaction, social support, subjective health, optimism). Thereafter, we aimed to conduct longitudinal analyses about the relationship between compassion and well-being, using those indicators of well-being that we had data available on 3 measurement points (i.e. positive affect, negative affect, and social support). Specifically, the second aim was to investigate whether the predictive pathways are more likely to proceed from compassion to positive affect, negative affect, and social support, or in the opposite direction. Finally, the third aim was to investigate whether dispositional compassion has long-term predictive power on the level of well-being, i.e. we investigated whether compassion predicts the level of social support over a 10-year follow-up and the composite of positive and negative affect (i.e. Affective Well-being Index) over a 15-year follow-up.

\section{Material and methods}

\subsection{Participants}


We used data from the prospective Young Finns Study (YFS). Participants were selected from the population register of the Social Insurance Institution that covers the whole population of Finland. The original sample included 3596 participants that were selected randomly from six age cohorts (born between 1962 and 1977). The baseline measurement was in 1980, and the participants have been followed since then so that the most recent measurement was in 2012 (participants were aged 35-50 years). For this study, dispositional compassion, and positive and negative affect were assessed in 1997, 2001, and 2012; social support in 1997, 2001, and 2007; life satisfaction, subjective health, and optimism in 2001; childhood socioeconomic factors in 1980; and adulthood socioeconomic factors in 2007. The measurement years are described in Supplementary Table 1. We included in the analyses all the participants with full data on each study variable in at least one of its measurement years. The final sample consisted of 1312-1699 participants in the analyses.

The study was carried out in accordance with the Declaration of Helsinki, and the study design was approved by the ethical committees of Finnish universities with medical schools. The participants or their parents provided their written informed consent. The design of the YFS is described in more detail elsewhere (Raitakari et al., 2008).

\subsection{Measures}

\subsubsection{Dispositional compassion}

Dispositional compassion was measured in 1997, 2001, and 2012 with the version 9 of the

Temperament and Character Inventory (TCI, Cloninger et al., 1994). Compassion is a subscale of character dimension Cooperativeness in the TCI. The compassion scale $(\alpha=.85-.87$ in 1997,2001 , and 2012) consists of 10 self-rating (e.g., "It gives me pleasure to see my enemies suffer" [reverse scored], "It gives me pleasure to help others, even if they have treated me badly" [positively scored], "I like to 
imagine my enemies suffering" [reverse scored] and "I hate to see anyone suffer" [positively scored]). The correlations between single items and the total score of the scale were high $(r=0.501-0.819$, $p<.001)$. We also conducted a confirmatory factor analysis of the Compassion Scale in order to investigate the structural validity of the scale. All the items (both reversely-scaled items and positivelyscaled items) were found to have significant loadings on the compassion factor $(r=0.366-0.844$, $p<.001)$. Moreover, the goodness-of-fit of the 1-factor model was excellent $(\mathrm{CFI}=0.993$; RMSEA=0.044). The results of the confirmatory factor analysis can be seen with further detail in Supplementary Figure 1. For each measurement year, we calculated a sum score of compassion for all the participants who had rated all the items.

Regarding psychometric properties, the test-retest reliability of the scale has been confirmed previously (e.g. Hansenne et al, 2005). Additionally, the validity of the dispositional compassion scale has been shown to be adequate. Specifically, high scores of the compassion scale correlate with higher social warmth toward others, higher altruistic behavior, and higher sociability (García et al., 2012; Schmidt et al., 2003). Low values of the compassion scale are linked with higher hostility and aggression toward others (García et al., 2012; Lee et al., 2012) and also higher narcissistic (De Fruyt et al., 2006) and psychopathic features (Paal et al., 2007).

\subsubsection{Affective well-being}

Affective well-being (consisting of positive and negative affect) was measured in 1997, 2001, and 2012.

In 1997 and 2001, positive affect was measured with the Mood scale of Revised Dimensions of Temperament Survey (DOTS-R) (Windle \& Lerner, 1986). The scale includes 7 items (e.g. "Generally I feel happy") that are rated with a 5-point Likert-scale ranging from 1 (fits me not at all) to 5 (fits me very well). For each measurement year, we calculated a sum score of the items for all 
the participants who had rated all the items. The internal consistency for the scale was high in 1997 and $2012(\alpha=.89-.91)$.

In 1997 and 2001, negative affect was assessed with the Negative Emotionality scale of the Emotionality, Activity, and Sociability (EAS) Temperament Survey (Buss, 1991). The scale consists of 12 items measuring anger and fear (e.g. "I have fewer fears than other people my age" [reverse scored]). The items are answered with a 5-point Likert-scale ranging from 1 (fits me not at all) to 5 (fits me very well). A sum score of the items was calculated for each measurement year. The internal consistency of the scale was $\alpha=.81$ in 1997 and 2001. The reliability and construct validity of the EAS have been confirmed also previously (e.g. Naerde et al., 2004).

In 2012, positive affect and negative affect were assessed with the Positive and Negative Affect Schedule (PANAS) (Watson \& Clark, 1994). The scale includes 10 items measuring the degree of different positive affects (e.g. excitement, alertness) and negative affects (e.g. shame, nervousness). Participants are asked to rate how much they feel each affect in general, ranging from 1 (not at all) to 5 (extremely). Previously, the psychometric properties of the PANAS are demonstrated to be excellent (Mackinnon et al., 1999; Thompson, 2007). In our sample, the internal consistency for the positive affect scale was $\alpha=.83$ and for the negative affect scale $\alpha=.76$.

The Affective Well-being Index referred to the presence of positive affect and negative affect. The index was calculated by subtracting the standardized score of negative affect from the standardized score of positive affect, as has been done also in previous studies (e.g. Cloninger \& Zohar, 2011; Josefsson et al., 2011). Hence, a higher value of the index referred to higher positive affect and lower negative affect.

\subsubsection{Cognitive well-being}

Indicators of cognitive well-being included perceived social support, life satisfaction, subjective health, 
and optimism. We had longitudinal data available on perceived social support, but only one time-point data available on the other indicators of cognitive well-being.

Perceived social support was assessed in 1997, 2001, and 2007 using the Multidimensional Scale of Perceived Social Support (MSPSS) (Zimet et al., 1988). The scale measures perceived social support from friends ( 4 items), family ( 4 items), and a significant other (4 items). The items (e.g. "My friends always help me, when I need help") are rated on a 5-point Likert-scale. For each measurement year, we calculated a sum score of the items for all the participants who had rated all the items. The internal consistency for the scale was high $(\alpha=.93-.95)$ in 1997-2007. The MSPSS has been shown to be a valid and reliable measure of perceived social support (Hardan-Khalil \& Mayo, 2015; Rajabi \& Hashemi-Shabani, 2011).

Life satisfaction was measured in 2001 with the question "How satisfied are you with your life?", which was answered with a 5-point Likert-scale (1=very satisfied; $2=$ rather satisfied; $3=$ neither satisfied nor unsatisfied; $4=$ rather satisfied; $5=$ very unsatisfied). The item was reversed so that a higher value referred to higher life satisfaction.

Subjective health was evaluated in 2001 with the question "What is your health like compared to others of your age?". The item was rated with a 5-point Likert-scale (1=very good; $2=$ rather good; $3=$ average; $4=$ rather bad; $5=$ very bad). The item was reversed so that a higher value referred to a better subjective health.

Optimism was evaluated with in 2001 the Revised Life Orientation Test (LOT-R) (Scheier et al., 1994). It consists of 10 items (e.g. "During uncertain times, I believe that things will usually be resolved in the best possible way") that are answered with a 5-point Likert-scale $(0=$ completely disagree; $4=$ completely agree $)$. The items were reversed so that a higher value referred to higher optimism. We calculated a sum score of optimism for all the participants who had rated all the items $(\alpha=.77)$. Previously, the psychometric properties of the scale are demonstrated to be excellent 
(Glaesmer et al., 2012; Herzberg et al., 2006).

The Cognitive Well-being Index in 2001 consisted of social support, life satisfaction, subjective health, and optimism. The index was calculated as the mean of standardized values (mean=0, SD=1) of life satisfaction, social support, subjective health, and optimism. Regarding the reliability of the cognitive well-being index, the internal consistency of the index was high (Cronbach's $\alpha=.819)$. Additionally, each single construct of cognitive well-being correlated strongly with the total score of the cognitive well-being index (i.e., optimism: $r=0.748$; life satisfaction: $r=0.744$; social support: $r=0.681$; subjective health: $r=0.635)$.

\subsubsection{Socioeconomic factors}

Socioeconomic factors in childhood (measured in 1980) included mother's educational level, father's educational level, and parental occupational status. Socioeconomic factors in adulthood (measured in 2007) included participant's educational level and occupational status. Educational level was classified into 3 categories $(1=$ comprehensive school; $2=$ high school or occupational school; $3=$ academic level). Occupational status was categorized as manual, lower grade non-manual, or upper grade non-manual. This classification has been used also previously (e.g. Pulkki-Råback et al., 2015). Socioeconomic factors were added as separate variables to all the analyses.

\subsection{Statistical analyses}

Statistical analyses were conducted with Stata SE version 13.0. Attrition was examined by comparing the included and excluded participants with regard to study variables using independent samples t-test and chi-square independence tests. We investigated the cross-sectional associations of compassion with affective and cognitive well-being using linear regression analyses. We predicted Affective Well-being Index, Cognitive Well-being Index, and all the single indicators of affective and cognitive well-being 
(i.e. positive affect, negative affect, life satisfaction, social support, subjective health, and optimism) by dispositional compassion. All the analyses were adjusted for age, gender, and socioeconomic factors in childhood and adulthood.

Secondly, we investigated the temporal relationships of dispositional compassion and well-being. We used those indicators of well-being that we had longitudinal data available at 3 measurement points (i.e. positive affect, negative affect, and social support). We used cross-lagged panel design for longitudinal data. Four models were estimated: (1) an autoregressive model with only stability coefficients (the only predictors of the variables at time point 2 were the same variables at time point 1 , and the only predictors of the variables at time point 3 were the same variables at time point 2) and covariances between dispositional compassion and well-being indicators within each timepoint; (2) a model including also cross-lagged predictive paths from dispositional compassion at each time-point to well-being indicators at the following timepoint; (3) a model including cross-lagged predictive paths in the opposite direction (i.e. from well-being indicators at each time-point to dispositional compassion at the following timepoint); (4) a model with the reciprocal cross-lagged predictive paths in both directions between dispositional compassion and indicators of well-being.

The statistical fit of the models 1-4 was assessed by the values of the Comparative Fit Index (CFI), the Root-Mean-Square Error of Approximation (RMSEA), and the Bayesian Information Criterion (BIC). Good values of the CFI are over 0.95 (Hu \& Bentler, 1999). The RMSEA value should be less than .06 (Hu \& Bentler, 1999). Additionally, lower values of BIC and chi-square test of absolute model fit indicate better model-fit (Schreiber et al., 2006).

Thirdly, we investigated whether compassion has long-term predictive power on the level of well-being over the total follow-up time (over 10 years). We used multilevel models using maximum likelihood estimation. Again, we used those indicators of well-being that we had longitudinal data available at 3 measurement points. We estimated separate growth curve models for for social support 
(measured in 1997, 2001, and 2007) and for the Affective Well-being Index (measured in 1997, 2001, and 2012). Intercept, compassion in 1997, follow-up time in years, follow-up time squared, the ageinteraction of compassion, age, gender, and socioeconomic factors were set as fixed effects. Intercept and follow-up time in years were treated also as random effects. Follow-up time was 15 years for the Affective Well-being Index and 10 years for social support.

Before conducting the statistical analyses, we checked that the statistical requirements for using linear regression analyses, structural equation models, and multilevel models were fulfilled (normality etc.).

\section{Results}

Descriptive statistics are shown in Table 1. Attrition analyses showed that women were more likely to participate than men $(40.8 \%$ vs. $33.1 \%, p<.001)$. Included participants were older than excluded participants $(31.74$ vs. $31.27, p<.01)$. There were no differences in the level of compassion, positive affect, or social support between included and excluded participants. However, included participants had slightly lower negative affect (30.77 vs. 31.88, $p<.01)$, a higher Affective Well-being Index (0.09 vs. $-0.15, p<.01)$, higher life satisfaction (4.05 vs. 3.94, $p<.01)$, better subjective health (3.95 vs. 3.82, $p<.01$ ), higher optimism (20.39 vs. 19.51, $p<.001)$, and a higher Cognitive Well-being Index (0.053 vs. $-0.095, p<.001)$ than excluded participants. Regarding socioeconomic factors, included participants were more likely to be upper grade non-manual workers $(49.1 \%$ vs. $40.4 \%, p<.001)$ and to have high educational level $(19.7 \%$ vs. $13.3 \%, p<.05)$ than excluded participants. Moreover, included participants' parents were less likely to have low educational level $(31.7 \%$ vs. $36.5 \%, p<.05)$ than excluded participants' parents. There was no attrition bias in parents' occupational status between included and excluded participants. 
[Table 1 about here]

Table 2 presents the cross-sectional associations of dispositional compassion with affective and cognitive well-being. Compassion was standardized to mean $=0$ and $\mathrm{SD}=1$. Hence, $\mathrm{B}$ refers to change in each indicator of well-being per one-unit change (i.e. 1-SD change) in compassion. All the associations were controlled for age, gender, and socioeconomic factors in childhood and adulthood. The results revealed that dispositional compassion was related to all indicators of well-being. Specifically, high dispositional compassion was associated with higher positive affect, lower negative affect, higher life satisfaction, higher social support, higher subjective health, and higher optimism. Moreover, high dispositional compassion was related to higher scores of the Affective Well-being Index and the Cognitive Well-being Index. The results of the linear regression analyses are described with more detail in Supplementary Tables 2 and 3 (including the coefficients of the control variables).

Additionally, we reran the analysis about compassion and cognitive well-being so that the single-item measures of the Cognitive Well-being Index (i.e. subjective health and life satisfaction) were excluded from the index. The association between compassion and cognitive well-being remained significant $(\mathrm{B}=0.251, p<0.001)$.

[Table 2 about here]

Table 3 presents the results of the cross-lagged analyses related to the temporal relationships of dispositional compassion with positive affect, negative affect, and social support (i.e. indicators of well-being that we had data available at 3 measurement points). All the models were controlled for age, gender, and socioeconomic factors in childhood and adulthood. The goodness-of-fit statistics showed 
that model 1 (autoregressive model without cross-lagged predictive paths) had relatively good fit (RMSEA=.057, CFI=.958, BIC=66546.589). Nevertheless, model 2 (cross-lagged paths from dispositional compassion to positive affect, negative affect, and social support) had significantly better fit than model $1(p<.001)$. Moreover, model 2 appeared to have better goodness-of-fit indices than model 3 (cross-lagged paths in the opposite direction, i.e. from positive affect, negative affect, and social support to dispositional compassion) with regard to all fit indices. Specifically, when compared to model 3, model 2 had lower values of $\chi^{2}$ test (212.595 vs. 251.536), RMSEA (0.056 vs. 0.061), and BIC (66541.666 vs. 66580.607), and also a higher value of CFI (0.966 vs. 0.959). Model 4 (crosslagged predictive paths in both directions) did not have better fit than model $2(p=.107)$. Taken together, cross-lagged analyses indicated that model 2 had slightly better fit than the other models. Hence, there appeared to exist slightly stronger predictive paths from dispositional compassion to positive affect, negative affect, and social support than in the opposite direction.

[Table 3 about here]

The predictive paths of the model 2 are presented in Figure 1. Figure 1 shows that all the stability coefficients (paths from the same variable from time point 1 to time point 2 and from time point 2 to time point 3) were significant $(p<.001)$. Generally, the cross-lagged predictive paths from compassion to positive affect, negative affect, and social support were comparatively modest by magnitude $(\beta=[-$ 0.08; 0.09]). Nevertheless, adding them to the model increased the statistical fit significantly. Compassion in 1997 predicted lower negative affect in $2001(p<.01)$ and higher social support in 2001 $(p<.001)$. Moreover, compassion in 2001 predicted higher positive affect in $2012(p<.01)$, lower negative affect in $2012(p<.01)$, and higher social support in $2007(p<.001)$. The path from compassion 
in 1997 to positive affect in 2001 was not significant. However, it is necessary to consider that in structural equation models, the statistical goodness-of-fit indices utilize the information of the full data, i.e. the regression coefficients, covariances, and stability coefficients over all the measurement points and between all the indicators of well-being and compassion. Hence, the goal of SEMs is to investigate predictive paths over multiple measurement points and multiple regression paths (not just single regression coefficients). Thus, there may exist single non-significant paths also in best-fitting model.

[Figure 1 about here]

Finally, we investigated whether compassion has long-term predictive power on the level of social support and Affective Well-being Index over the total follow-up time (over 10 years) (Table 4). All the multilevel models were controlled for age, gender, and socioeconomic factors in childhood and adulthood. The results showed that high dispositional compassion in 1997 predicted a higher Affective Well-being Index over the 15-year follow-up and higher social support over the 10-year follow-up. However, the effect of compassion on the Affective Well-being Index and social support became slightly weaker over the follow-up, as indicated by the negative interaction effect between compassion and follow-up time in years. The results of the multilevel models are illustrated in Figure 2.

[Table 4 about here]

[Figure 2 about here]

\section{Discussion}


The present study was the first to investigate the relationship of compassion with affective and cognitive well-being over a follow-up of several years and several assessment points. Our results showed that high dispositional compassion was related to a wide variety of indicators of affective and cognitive well-being. The effect of compassion on positive affect, negative affect, social support, optimism, and life satisfaction was comparatively strong by effect size $(\mathrm{B}=0.15-0.36)$, indicating also practical significance of the results. Only the association between compassion and subjective health was slightly smaller by effect size $(B=0.09)$. We also found that there were slightly stronger predictive pathways from high compassion to higher positive affect, lower negative affect, and higher social support than in the opposite direction. Finally, the results demonstrated that high dispositional compassion has long-term predictive power on the level of well-being. Specifically, high compassion predicted higher Affective Well-being Index over a 15-year follow-up and higher social support over a 10-year follow-up. All the results were sustained after controlling for age, gender, and socioeconomic factors in childhood and adulthood.

In line with a previous study (Steffen \& Masters, 2005), we found that high compassion was related to higher social support. Previous evidence indicates that compassionate individuals are have more affiliative goals in social relationships (Crocker et al., 2009). Additionally, compassionrelated interventions are suggested to enhance the quality of interpersonal relationships (Bao \& Lyubomirsky, 2014) and reduce the feelings of social marginalization (Kirby et al., 2017).

Furthermore, our findings revealed that high dispositional compassion was also related to an array of other indicators of cognitive well-being, including higher subjective health, higher optimism, and higher life satisfaction. The link between high compassion and better subjective health is in line with previous findings. Specifically, it has been found that high compassion is linked to more favorable health behaviors, such as lower risk for smoking and substance use (Evren et al., 2007; Schiep \& Cieślik, 2011) and may also protect against somatization symptoms (Clarke, 2016; Cloninger \& 
Docuku, 2016). Moreover, compassion interventions may alleviate a range of psychiatric symptoms, such as depression and anxiety (Balsamo et al., 2013; Lucre \& Corten, 2013; Richter et al., 2000). High optimism, in turn, is conceptually close to high compassion since compassion includes by definition the willingness to alleviate others' suffering (Goetz et al., 2010) and, hence, a positive expectation about the outcomes of helping behavior. With regard to the link of compassion with higher satisfaction, it is widely known that life satisfaction commonly derives from goal attainment (e.g. Ryan \& Deci, 2001). One fundamental goal in human's life is to live in harmony with important others and avoid social exclusion (e.g. Sheldon \& Elliott, 1999). This goal may likely be promoted by high compassion since it is related to social warmth (Schmidt et al., 2013) and better social functioning (Goetz et al., 2010).

Our findings demonstrated that the effect of dispositional compassion on higher Affective Well-being Index was evident over a 15-year follow-up and on higher social support over a 10-year follow-up in adulthood. Additionally, the effect size of these associations was comparatively high $(\mathrm{B}=$ $\mathrm{B}=0.23$ for social support and $\mathrm{B}=0.36$ for Affective Well-being Index), indicating that the associations have also practical significance. Hence, compassion may not only predict temporary states of positive affect but also more stable and longer-lasting well-being. The enduring effect of compassion may be related to the physiological and neurochemical basis of compassion. For example, there is evidence for a link between compassion and genetic factors (Jönsson et al., 2003; Pełka-Wysiecka et al., 2012), cardiovascular responses (e.g. heart rate, respiratory sinus arrhythmia) (Kirby et al., 2017a; Stellar et al., 2016), and certain cytokines (Pace et al., 2009). Further, brain imaging studies have demonstrated that compassion interventions may alter the neural processing of affective stimuli in subcortical circuitries, such as amygdala, anterior insula, anterior cingulate, hypothalamus, mesencephalon, posteromedial cortices (Immordino-Yang et al., 2009; Lutz et al., 2008). In the future, compassionrelated alterations in brain functioning could be investigated more thoroughly, using a wider range of research designs. 
Previously, it has been suggested that self-related characteristics such as autonomy, fulfillment of one's potential, or making the most of one's talents might promote happiness and wellbeing (Jayawickreme et al., 2012; Weinstein \& Ryan, 2010). This, in turn, is suggested to provide resources to form close and supportive relationships, to give one's contribution to social communities, and to alleviate others' suffering (Jayawickreme et al., 2012). Additionally, previous studies have found that positive affect may increase prosocial behavior in close relationships (Cavanaugh et al., 2015; Lyubomirsky et al., 2005). Hence, this implies that certain level of well-being might help feel compassion for others.

Our findings, however, suggested that there might be a slightly stronger temporal relationship from compassion to well-being (i.e. higher positive affect, lower negative affect, higher social support) than in the opposite direction. The predictive paths from compassion to well-being were seemingly comparatively low $(\mathrm{B}=[-0.08 ; 0.08])$. However, it has been highlighted that the effect sizes of the path coefficients in structural equation models should not be interpreted in accord with the universal guidelines (Adachi \& Willoughby, 2015). That is, if the study variables are highly stable (i.e. stability coefficients are high), the coefficients of the predictive paths may be seemingly low, even though the predictive paths would have practical significance (Adachi \& Willoughby, 2015). In this study, the stability coefficients were high (e.g. for compassion $B=0.68-0.70$ ). Hence, despite the seemingly low path coefficients, the predictive paths between compassion and well-being are likely to have practical significance. Nevertheless, it is necessary to consider that the predictive relationships may exist to some extent in both directions since the goodness-of-fit of such a model, which included paths from well-being to compassion, was also very good. Taken together, what may be concluded from our findings is that psychological well-being seems not to be a necessary requirement for feeling compassionate for others. In this way, the findings provide a hopeful and encouraging perspective that 
individuals living in unfavorable psychosocial circumstances may not have inevitable difficulties to be compassionate for others.

The present study had some methodological limitations that are necessary to be taken into consideration. Firstly, attrition analyses revealed that there was no attrition bias in the level of compassion. However, included participants had slightly lower negative affect, higher Affective Wellbeing Index, higher life satisfaction, better subjective health, and higher optimism than excluded participants. Taken together, there appeared to be a bias toward higher well-being in our sample. It has been common also in previous studies that subjects with better mental health are more likely to participate in the follow-up measurements (e.g. Graaf et al., 2000; Vincent et al., 2012). Furthermore, in our study, the differences between included and excluded participants was minor by effect size in most variables. Hence, the attrition bias may not likely have any practical significance.

Secondly, compassion and affective and cognitive well-being were evaluated with selfrating questionnaires that may be susceptible for desirable responding. Hence, the results may potentially have been affected by a common methods bias: that is, some common variance between study variables may be partly accounted by the common measurement method (Gorrell et al., 2011; Podsakoff et al., 2003). Subjective experiences of well-being are, however, challenging characteristics to measure accurately with other methods. Moreover, our multivariate covariance analyses included several predictive variables that were measured with self-rating scales. This has been found to decrease the magnitude of common methods bias (Siemsen et al., 2010). Additionally, our cross-lagged analyses and multilevel models included quadratic slopes and interaction effects, which are more likely deflated than inflated by the common methods bias (Siemsen et al., 2010). Finally, the time lag between different measurements was likely to decrease the amount of common methods bias in our study. Consequently, our results are not likely to be artifacts of the common methods bias. 
Thirdly, the measure of positive and negative affect changed during the follow-up. That is, negative affect was measured with the EAS and positive affect with the DOTS-R in 1997 and 2001, but in 2012 they were assessed with the PANAS. Nevertheless, our results were not affected by the differences in the scaling of the separate questionnaires, since we used the standardized scores of positive and negative affect. Additionally, our cross-lagged analyses showed that the stability coefficients from the year 2001 scores of positive and negative affect to the year 2012 scores were highly significant. This indicated that the stability of positive and negative affect was high over the 15year follow-up despite the change of the measures. Additionally, also previous research has shown a strong link of the PANAS affectivity with the emotionality scales of the EAS (Anthony et al., 2002) and also with the mood scale of the DOTS-R (Gumora \& Arsenio, 2002). Hence, these measures of affectivity seem to be relatively strongly connected with each other. Finally, all the scales that we used in this study have been widely used and validated (e.g. Mackinnon et al., 1999; Naerde et al., 2004; Thompson, 2007).

Beyond the limitations, our study had also a variety of significant strengths. This study was the first to investigate the role of dispositional compassion for well-being using a longitudinal design. Our data included a prospective follow-up period of 15 years and several assessment points of compassion and well-being. This kind of longitudinal study has been called for in a recent metaanalysis (Zessin et al., 2015) and also in two reviews on well-being (McNulty \& Fincham, 2012; Post, 2005). Moreover, our analyses were conducted in relatively large samples including 1312-1699 participants. In addition, we had a wide range of indicators for well-being (i.e. positive and negative affect, social support, life satisfaction, subjective health, optimism), which has also been called for previously (Zessin et al., 2015). Finally, we could control for a variety of potential confounding factors, such as age, gender, and socioeconomic factors in childhood and adulthood. 
Previously, it has been shown that compassion can be intentionally cultivated by compassion interventions, including, for example, practicing to imagine the suffering of others and the changes in their feelings after alleviating this suffering, and exercises to become aware of the psychosomatic experiences related to compassion (Kirby, 2017; Kirby et al., 2017b; Jazaieri et al., 2013; Mongrain et al., 2011). It has been stated that the most necessary skills required for participation in compassion intervention are abilities to concentrate and settle one's mind (Hofmann et al., 2011; Jazaieri et al., 2013). Instead, advanced metacognitive abilities or skills for reflecting one's mental processes may not necessarily be needed. Moreover, even a few-week-long compassion intervention may have positive influences on compassion development (Jazaieri et al., 2013). Consequently, compassion interventions might potentially be a comparatively cost-effective way to enhance wellbeing.

With regard to practical implications, current positive psychology interventions are focused on promoting empathy, prosociality, forgiveness, and purpose in life (Parks \& Schueller, 2014; Schroeder \& Graziano, 2015). Our findings, in turn, suggested that increasing compassion for others is likely to support individual's well-being in adulthood. Even though there are similarities between empathy- and compassion-focused interventions, they also differ from each other in several essential ways. For example, empathy training aims to increase sharing of others' affective states and communication of one's parallel emotions (Davis \& Begovic, 2014), whereas compassion training aims to promote one's abilities to tolerate others' suffering and take behavioral steps to alleviate it (Kirby \& Gilbert, 2017). Moreover, empathy training is commonly used to target the challenges of a specific relationship (e.g. parent-child or romantic partnership) (Davis \& Begovic, 2014), whereas compassion training aims to promote compassionate feelings toward other people in general (Kirby \& Gilbert, 2017). Taken together, compassion-focused interventions might provide new tools for positive psychology interventions. 


\section{Acknowledgments}

This study was supported financially by the Academy of Finland (M.H., grant number 308676); the Jenny and Antti Wihuri Foundation (L.P.-R.), and the Yrjö Jahnsson Foundation (L.P.-R.). The Young Finns Study has been financially supported by the Academy of Finland: grants 286284, 134309 (Eye), 126925, 121584, 124282, 129378 (Salve), 117787 (Gendi), and 41071 (Skidi); the Social Insurance Institution of Finland; Competitive State Research Financing of the Expert Responsibility area of Kuopio, Tampere and Turku University Hospitals (grant X51001); Juho Vainio Foundation; Paavo Nurmi Foundation; Finnish Foundation for Cardiovascular Research ; Finnish Cultural Foundation; The Sigrid Juselius Foundation; Tampere Tuberculosis Foundation; Emil Aaltonen Foundation; Yrjö Jahnsson Foundation; Signe and Ane Gyllenberg Foundation (T.L); Diabetes Research Foundation of

Finnish Diabetes Association; and EU Horizon 2020 (grant 755320 for TAXINOMISIS); and European Research Council (grant 742927 for MULTIEPIGEN project); Tampere University Hospital Supporting Foundation.

\section{Role of the funding source}

The funding source had no role in study design, data collection, data analysis, data interpretation, writing of the report, or in the decision to submit the article for publication.

\section{References}

Adachi, P., \& Willoughby, T. (2015). Interpreting effect sizes when controlling for stability effects in longitudinal autoregressive models: Implications for psychological science. European Journal of Developmental Psychology, 12, 116-128. 
Anthony, J. L., Lonigan, C. J., Hooe, E. S., \& Phillips, B. M. (2002). An affect-based, hierarchical model of temperament and its relations with internalizing symptomatology. Journal of Clinical Child and Adolescent Psychology, 31, 480-490.

Balsamo, M. (2013). Personality and depression: evidence of a possible mediating role for anger trait in the relationship between cooperativeness and depression. Comprehensive Psychiatry, 54, 46-52.

Bao, K. J, \& Lyubomirsky, S. (2014). Making happiness to last: Using the hedonic adaptation prevention model to extend the success of positive interventions. In The Wiley Blackwell Handbook of Positive Psychological Interventions, pp. 373-384, by A. C. Parks \& S. M. Schueller (Eds). The John Wiley \& Sons Ltd, UK.

Barnard, L. K., \& Curry, J. F. (2011). Self-compassion: Conceptualizations, correlates, \& interventions. Review of General Psychology, 15.

Buchanan, K. E., \& Bardi, A. (2010). Acts of kindness and acts of novelty affect life satisfaction. Journal of Social Psychology, 150, 235-237.

Buss, A.H. (1991). The EAS theory of temperament. In: Strelau, J., Angleitner, A. (Eds.), Explorations in Temperament: International Perspectives on Theory and Measurement. Plenum Press, New York, pp. 43-60.

Catarino, F., Gilbert, P., McEwan, K., \& Baião, R. (2014). Compassion motivations: Distinguishing submissive compassion from genuine compassion and its association with shame, submissive behavior, depression, anxiety and stress. Journal of Social and Clinical Psychology, 33, 399-412.

Cavanaugh, L. A., Bettman, J. R., \& Luce, M. F. (2015). Feeling love and doing more for distant others: Specific positive emotions differentially affect prosocial consumption. Journal of Marketing Research, 52, 657-673.

Clarke, D. D. (2016). Diagnosis and treatment of medically unexplained symptoms and chronic functional syndromes. Families, Systems, \& Health, 34, 309-316. 
Cloninger, C. R., \& Dokucu, M. (2016). Somatizing and Dissociative Disorders. In The Medical Basis of Psychiatry (pp. 195-209). Springer, New York, NY.

Cloninger, C. R., Przybeck, T. R., Svrakic, D. M., \& Wetzel, R. D. (1994). The Temperament and Character Inventory (TCI): A guide to its development and use.

Cloninger, C. R., \& Zohar, A. H. (2011). Personality and the perception of health and happiness. Journal of Affective Disorders, 128, 24-32.

Crocker, J., Olivier, M. A., \& Nuer, N. (2009). Self-image goals and compassionate goals: Costs and benefits. Self and Identity, 8, 251-269.

Cusi, A. M., MacQueen, G. M., Spreng, R. N., \& McKinnon, M. C. (2011). Altered empathic responding in major depressive disorder: relation to symptom severity, illness burden, and psychosocial outcome. Psychiatry Research, 188, 231-236.

Davis, M. H., \& Begovic, E. (2014). Empathy-Related Interventions. In: A. C. Parks, \& S. Schueller (Eds): The Wiley Blackwell Handbook of Positive Psychological Interventions. John Wiley \& Sons.

De Fruyt, F., De Clercq, B. J., van de Wiele, L., \& Van Heeringen, K. (2006). The validity of Cloninger's Psychobiological Model versus the Five-Factor Model to predict DSM-IV personality disorders in a heterogeneous psychiatric sample: Domain facet and residualized descriptions. Journal of Personality, 74, 479-510.

Diener, E., Oishi, S., \& Lucas, R. E. (2003). Personality, culture, and subjective well-being: Emotional and cognitive evaluations of life. Annual Review of Psychology, 54, 403-425.

Di Tella, R., Haisken-De New, J., \& MacCulloch, R. (2010). Happiness adaptation to income and to status in an individual panel. Journal of Economic Behavior \& Organization, 76, 834-852.

Duarte, J. L. (2014). Beyond Life Satisfaction: A Scientific Approach to Well-Being Gives Us Much More to Measure. In The Wiley Blackwell Handbook of Positive Psychological Interventions, pp. 433-449, by A. C. Parks \& S. M. Schueller (Eds). The John Wiley \& Sons Ltd, UK. 
Evren, C., Evren, B., Yancar, C., \& Erkiran, M. (2007). Temperament and character model of personality profile of alcohol-and drug-dependent inpatients. Comprehensive Psychiatry, 48, 283288.

Fujiwara, T. (2007). The role of altruistic behavior in generalized anxiety disorder and major depression among adults in the United States. Journal of Affective Disorders, 101, 219-225.

García, Ó., Aluja, A., García, L. F., Escorial, S., \& Blanch, A. (2012). Zuckerman-Kuhlman-Aluja Personality Questionnaire (ZKA-PQ) and Cloninger's Temperament and Character Inventory Revised (TCI-R): A comparative study. Scandinavian Journal of Psychology, 53, 247-257.

Gilbert, P. (2010). An introduction to compassion focused therapy in cognitive behavior therapy. International Journal of Cognitive Therapy, 3, 97-112.

Gilbert, P., \& Procter, S. (2006). Compassionate mind training for people with high shame and selfcriticism: Overview and pilot study of a group therapy approach. Clinical Psychology \& Psychotherapy, 13, 353-379.

Glaesmer, H., Rief, W., Martin, A., Mewes, R., Brähler, E., Zenger, M., \& Hinz, A. (2012). Psychometric properties and population-based norms of the Life Orientation Test Revised (LOTR). British Journal of Health Psychology, 17, 432-445.

Goetz, J. L., Keltner, D., \& Simon-Thomas, E. (2010). Compassion: an evolutionary analysis and empirical review. Psychological Bulletin, 136, 351-374.

Graaf, R. D., Bijl, R. V., Smit, F., Ravelli, A., \& Vollebergh, W. A. (2000). Psychiatric and sociodemographic predictors of attrition in a longitudinal study The Netherlands Mental Health Survey and Incidence Study (NEMESIS). American Journal of Epidemiology, 152, 1039-1047.

Gumora, G., \& Arsenio, W. F. (2002). Emotionality, emotion regulation, and school performance in middle school children. Journal of School Psychology, 40, 395-413. 
Hansenne, M., Delhez, M., \& Cloninger, C. R. (2005). Psychometric properties of the Temperament and Character Inventory-Revised (TCI-R) in a Belgian sample. Journal of Personality Assessment, $85,40-49$.

Hardan-Khalil, K., \& Mayo, A. M. (2015). Psychometric properties of the multidimensional scale of perceived social support. Clinical Nurse Specialist, 29, 258-261.

Hauge, L. J., Skogstad, A., \& Einarsen, S. (2009). Individual and situational predictors of workplace bullying: Why do perpetrators engage in the bullying of others. Work \& Stress, 23, 349-358.

Hershcovis, M. S., Turner, N., Barling, J., Arnold, K. A., Dupré, K. E., Inness, M., LeBlanc, M. M., \& Sivanathan, N. (2007). Predicting workplace aggression: a meta-analysis. Journal of Applied Psychology, 92, 228-238.

Herzberg, P. Y., Glaesmer, H., \& Hoyer, J. (2006). Separating optimism and pessimism: a robust psychometric analysis of the revised Life Orientation Test (LOT-R). Psychological Assessment, 18, 433-438.

Hofmann, S.G., Grossman, P. \& Hinton, D.E. (2011). Loving-kindness and compassion meditation: potential for psychological interventions. Clinical Psychology Review, 31, 1126-1132.

Hunot, V., Moore, T. H., Caldwell, D. M., Furukawa, T. A., Davies, P., Jones, H., ... \& Churchill, R. (2013). 'Third wave'cognitive and behavioural therapies versus other psychological therapies for depression. Cochrane Database of Systematic Reviews, 10.

Huppert, F. A., \& So, T. T. (2013). Flourishing across Europe: Application of a new conceptual framework for defining well-being. Social Indicators Research, 110, 837-861.

Immordino-Yang, M. H., McColl, A., Damasio, H., \& Damasio, A. (2009). Neural correlates of admiration and compassion. Proceedings of the National Academy of Sciences, 106, 8021-8026.

Jayawickreme, E., Forgeard, M. J., \& Seligman, M. E. (2012). The engine of well-being. Review of General Psychology, 16, 327-342. 
Jazaieri, H., Jinpa, G. T., McGonigal, K., Rosenberg, E. L., Finkelstein, J., Simon-Thomas, E., Cullen, M., Doty, J. R., Gross, J. J., \& Goldin, P. R. (2013). Enhancing compassion: a randomized controlled trial of a compassion cultivation training program. Journal of Happiness Studies, 14, 1113-1126.

Josefsson, K., Cloninger, C. R., Hintsanen, M., Jokela, M., Pulkki-Råback, L., \& Keltikangas-Järvinen, L. (2011). Associations of personality profiles with various aspects of well-being: a population-based study. Journal of Affective Disorders, 133, 265-273.

Judge, L., Cleghorn, A., McEwan, K., \& Gilbert, P. (2012). An exploration of group-based compassion focused therapy for a heterogeneous range of clients presenting to a community mental health team. International Journal of Cognitive Therapy, 5, 420-429.

Jönsson, E. G., Burgert, E., Crocq, M. A., Gustavsson, J. P., Forslund, K., Mattila-Evenden, M., ... \& Åsberg, M. (2003). Association study between dopamine D3 receptor gene variant and personality traits. American Journal of Medical Genetics Part B: Neuropsychiatric Genetics, 117, 61-65.

Kahneman, D. (1999). Objective happiness. In: D. Kahneman, E. Diener, \& N. Schwarz (ed.), Wellbeing: The Foundations of Hedonic Psychology (pp. 3-25). New York, NY: Russell Sage Foundation.

Kashdan, T. B., Biswas-Diener, R., \& King, L. A. (2008). Reconsidering happiness: The costs of distinguishing between hedonics and eudaimonia. Journal of Positive Psychology, 3, 219-233.

Keyes, C. L. M. (2002). The mental health continuum: From languishing to flourishing in life. Journal of Health and Social Behavior, 43, 207-222.

Kirby, J. N. (2017). Compassion interventions: the programmes, the evidence, and implications for research and practice. Psychology and Psychotherapy: Theory, Research and Practice, 90, 432-455. Kirby, J. N., Doty, J. R., Petrocchi, N., \& Gilbert, P. (2017a). The current and future role of heart rate variability for assessing and training compassion. Frontiers in Public Health, 5, 40. 
Kirby, J \& Gilbert, P. (2017). The emergence of the Compassion Focused Therapies. In: P. Gilbert (Ed). Compassion: Concepts, Research and Applications (p. 258-285). London: Routledge.

Kirby, J. N., Tellegen, C. L., \& Steindl, S. R. (2017b). A meta-analysis of compassion-based interventions: Current state of knowledge and future directions. Behavior Therapy, 48, 778-792.

Klimecki, O. M., Leiberg, S., Ricard, M., \& Singer, T. (2013). Differential pattern of functional brain plasticity after compassion and empathy training. Social Cognitive and Affective Neuroscience, 9, 873-879.

Lee, J., Min, S. K., Kim, K.-H., Kim, B., Cho, S. J., Lee, S.-H., . . Suh, S.-Y. (2012). Differences in temperament and character dimensions of personality between patients with Hwa-byung, an anger syndrome, and patients with major depressive disorder. Journal of Affective Disorders, 138, 110116.

Lewis, S. F., \& Fremouw, W. (2001). Dating violence: A critical review of the literature. Clinical Psychology Review, 21, 105-127.

Lucas, R. E. (2007). Adaptation and the set-point model of subjective well-being: Does happiness change after major life events. Current Directions in Psychological Science, 16, 75-79.

Lucre, K. M., \& Corten, N. (2013). An exploration of group compassion-focused therapy for personality disorder. Psychology and Psychotherapy: Theory, Research and Practice, 86, 387-400.

Luhmann, M., Hofmann, W., Eid, M., \& Lucas, R. E. (2012). Subjective well-being and adaptation to life events: a meta-analysis. Journal of Personality and Social Psychology, 102, 592-615.

Lutz, A., Brefczynski-Lewis, J., Johnstone, T., \& Davidson, R. J. (2008). Regulation of the neural circuitry of emotion by compassion meditation: effects of meditative expertise. PloS One, 3, e1897. Lyubomirsky, S., King, L., \& Diener, E. (2005). The benefits of frequent positive affect: Does happiness lead to success? Psychological Bulletin, 131, 803. 
Mackinnon, A., Jorm, A. F., Christensen, H., Korten, A. E., Jacomb, P. A., \& Rodgers, B. (1999). A short form of the Positive and Negative Affect Schedule: Evaluation of factorial validity and invariance across demographic variables in a community sample. Personality and Individual Differences, 27, 405-416.

Maslow, A. H. (1971). The farther reaches of human nature. New York, NY: Penguin.

McNulty, J. K., \& Fincham, F. D. (2012). Beyond positive psychology? Toward a contextual view of psychological processes and well-being. American Psychologist, 67, 101-110.

Međedović, J. (2017). Aberrations in emotional processing of violence-dependent stimuli are the core features of sadism. Motivation and Emotion, 41, 273-283.

Meyers, M. C., van Woerkom, M., \& Bakker, A. B. (2013). The added value of the positive: A literature review of positive psychology interventions in organizations. European Journal of Work and Organizational Psychology, 22, 618-632.

Mongrain, M., Chin, J. M., \& Shapira, L. B. (2011). Practicing compassion increases happiness and self-esteem. Journal of Happiness Studies, 12, 963-981.

Naerde, A., Roysamb, E., \& Tambs, K. (2004). Temperament in adults-reliability, stability, and factor structure of the EAS temperament survey. Journal of Personality Assessment, 82, 71-79.

Neff, K. D., \& Pommier, E. (2013). The relationship between self-compassion and other-focused concern among college undergraduates, community adults, and practicing meditators. Self and Identity, 12, 160-176.

Nowok, B., Van Ham, M., Findlay, A. M., \& Gayle, V. (2013). Does migration make you happy? A longitudinal study of internal migration and subjective well-being. Environment and Planning A, 45, 986-1002.

O’Connor, L. E., Berry, J. W., Weiss, J., \& Gilbert, P. (2002). Guilt, fear, submission, and empathy in depression. Journal of Affective Disorders, 71, 19-27. 
Paal, T., \& Bereczkei, T. (2007). Adult theory of mind, cooperation, Machiavellianism: The effect of mindreading on social relations. Personality and Individual Differences, 43, 541-551.

Pace, T. W., Negi, L. T., Adame, D. D., Cole, S. P., Sivilli, T. I., Brown, T. D., ... \& Raison, C. L. (2009). Effect of compassion meditation on neuroendocrine, innate immune and behavioral responses to psychosocial stress. Psychoneuroendocrinology, 34, 87-98.

Parks, A. C., \& Schueller, S. (Eds.) (2014). The Wiley Blackwell Handbook of Positive Psychological Interventions. John Wiley \& Sons.

Pełka-Wysiecka, J., Ziętek, J., Grzywacz, A., Kucharska-Mazur, J., Bienkowski, P., \& Samochowiec, J. (2012). Association of genetic polymorphisms with personality profile in individuals without psychiatric disorders. Progress in Neuro-Psychopharmacology and Biological Psychiatry, 39, 4046.

Post, S. G. (2005). Altruism, happiness, and health: It's good to be good. International Journal of Behavioral Medicine, 12, 66-77.

Pulkki-Råback, L., Elovainio, M., Hakulinen, C., Lipsanen, J., Hintsanen, M., Jokela, M., Kubzansky, L. D., Hintsa, T., Serlachius, A., Laitinen, T. T., Pahkala, K., Mikkilä, V., Nevalainen, J., HutriKähönen, N., Juonala, M., Viikasi, J., Raitakari, O., \& Keltikangas-Järvinen, L. (2015). Cumulative effect of psychosocial factors in youth on ideal cardiovascular health in adulthood: the Cardiovascular Risk in Young Finns Study. Circulation, 113.

Raitakari, O. T., Juonala, M., Rönnemaa, T., Keltikangas-Järvinen, L., Räsänen, L., Pietikäinen, M.,..., Jula, A. (2008). Cohort profile: the cardiovascular risk in Young Finns Study. International Journal of Epidemiology, 37, 1220-1226.

Rajabi, G., \& Hashemi-Shabani, S. E. (2011). The study of psychometric properties of the Multidimensional Scale Perceived Social Support. International Journal of Behavioral Sciences, 5, $357-364$. 
Richter, J., Eisemann, M., \& Richter, G. (2000). Temperament and character during the course of unipolar depression among inpatients. European Archives of Psychiatry and Clinical Neuroscience, 250, 40-47.

Ruini, C., Ottolini, F., Rafanelli, C., Tossani, E., Ryff, C. D., \& Fava, G. A. (2003). The relationship of psychological well-being to distress and personality. Psychotherapy and Psychosomatics, 72, 268275.

Ryan, R. M., \& Deci, E. L. (2001). On happiness and human potentials: A review of research on hedonic and eudaimonic well-being. Annual Review of Psychology, 52, 141-166.

Ryff, C. D. (1989). Happiness is everything, or is it? Explorations on the meaning of psychological well-being. Journal of Personality and Social Psychology, 57, 1069-1081.

Ryff, C. D. (2014). Psychological well-being revisited: Advances in the science and practice of eudaimonia. Psychotherapy and Psychosomatics, 83, 10-28.

Ryff, C. D., Love, G. D., Urry, H. L., Muller, D., Rosenkranz, M. A., Friedman, E. M., ... \& Singer, B. (2006). Psychological well-being and ill-being: do they have distinct or mirrored biological correlates. Psychotherapy and Psychosomatics, 75, 85-95.

Seligman, M. E. P. (2011). Flourish. New York, NY: The Free Press.

Sellström, E., \& Bremberg, S. (2006). The significance of neighbourhood context to child and adolescent health and well-being: a systematic review of multilevel studies. Scandinavian Journal of Public Hhealth, 34, 544-554.

Seppala, E., Rossomando, T., \& Doty, J. R. (2013). Social connection and compassion: important predictors of health and well-being. Social Research, 80, 411-430.

Scheier, M. F., Carver, C. S., \& Bridges, M. W. (1994). Distinguishing optimism from neuroticism (and trait anxiety, self-mastery, and self-esteem): a reevaluation of the Life Orientation Test. Journal of Personality and Social Psychology, 67, 1063-1078. 
Schieman, S., \& Turner, H. A. (2001). "When feeling other people's pain hurts": The influence of psychosocial resources on the association between self-reported empathy and depressive symptoms. Social Psychology Quarterly, 376-389.

Schiep, S., \& Cieślik, K. (2011). Personality dimensions and nicotine dependence and withdrawal symptoms: the mediating role of self-directness. Polish Psychological Bulletin, 42, 169-177.

Schmidt, K. M., Llewellyn, P. L., Taylor, G. J., Weber, P. G., Hong, B., Sellers, R., Wise, C., Wolak, C., McGaw, L., \& Nielson, S. (2003). Cloninger's Temperament and Character Inventory Correlates with Personality Characteristics of Organ Donation Advocates. Journal of Clinical Psychology in Medical Settings, 10, 173-185.

Schroeder, D. A., \& Graziano, W. G. (Eds.) (2015). The Oxford Handbook of Prosocial Behavior. Oxford Library of Psychology.

Sheldon, K. M., \& Elliot, A. J. (1999). Goal striving, need satisfaction, and longitudinal well-being: the self-concordance model. Journal of Personality and Social Psychology, 76, 482-497.

Sin, N. L., \& Lyubomirsky, S. (2009). Enhancing well-being and alleviating depressive symptoms with positive psychology interventions: A practice-friendly meta-analysis. Journal of Clinical Psychology, 65, 467-487.

Singer, T., \& Klimecki, O. M. (2014). Empathy and compassion. Current Biology, 24, R875-R878.

Steel, Z., Marnane, C., Iranpour, C., Chey, T., Jackson, J. W., Patel, V., \& Silove, D. (2014). The global prevalence of common mental disorders: a systematic review and meta-analysis 19802013. International Journal of Epidemiology, 43, 476-493.

Steffen, P. R., \& Masters, K. S. (2005). Does compassion mediate the intrinsic religion-health relationship. Annals of Behavioral Medicine, 30, 217-224. 
Stellar, J. E., Cohen, A., Oveis, C., \& Keltner, D. (2015). Affective and physiological responses to the suffering of others: Compassion and vagal activity. Journal of Personality and Social Psychology, $108,572-585$.

Steverink, N., Westerhof, G. J., Bode, C., \& Dittmann-Kohli, F. (2001). The personal experience of aging, individual resources, and subjective well-being. The Journals of Gerontology Series B: Psychological Sciences and Social Sciences, 56, P364-P373.

Thomas, M. R., Dyrbye, L. N., Huntington, J. L., Lawson, K. L., Novotny, P. J., Sloan, J. A., \& Shanafelt, T. D. (2007). How do distress and well-being relate to medical student empathy? A multicenter study. Journal of General Internal Medicine, 22, 177-183.

Thompson, E. R. (2007). Development and validation of an internationally reliable short-form of the positive and negative affect schedule (PANAS). Journal of Cross-Cultural Psychology, 38, 227-242.

Vincent, K. B., Kasperski, S. J., Caldeira, K. M., Garnier-Dykstra, L. M., Pinchevsky, G. M., O’Grady, K. E., \& Arria, A. M. (2012). Maintaining superior follow-up rates in a longitudinal study: Experiences from the College Life Study. International Journal of Multiple Research Approaches, 6, $56-72$.

Waterman, A. S. (2008). Reconsidering happiness: An Eudaimonist's perspective. Journal of Positive Psychology, 3, 234-252.

Watson, D. \& Clark, L. A. (1994). The PANAS-X. Manual for the Positive and Negative Affect Scheduled - Expanded Form. Iowa City, IA: University of Iowa.

Weinstein, N., \& Ryan, R. M. (2010). When helping helps: autonomous motivation for prosocial behavior and its influence on well-being for the helper and recipient. Journal of Personality and Social Psychology, 98, 222-244. 
Windle, M., \& Lerner, R. M. (1986). Reassessing the dimensions of temperamental individuality across the life span: The Revised Dimensions of Temperament Survey (DOTS-R). Journal of Adolescent Research, 1, 213-229.

Zessin, U., Dickhäuser, O., \& Garbade, S. (2015). The relationship between self-compassion and wellbeing: A meta-analysis. Applied Psychology: Health and Well-Being, 7, 340-364.

Zimet, G. D., Dahlem, N. W., Zimet, S. G., \& Farley, G. K. (1988). The multidimensional scale of perceived social support. Journal of Personality Assessment, 52, 30-41. 
Table 1. Means, standard deviations (SD), and frequencies of the study variables.

\begin{tabular}{|c|c|c|c|}
\hline & Mean & SD & Frequency \\
\hline Dispositional compassion (in 2001) & 36.730 & 6.432 & \\
\hline \multicolumn{4}{|l|}{ Affective well-being (in 2001) } \\
\hline Positive affect & 28.848 & 4.967 & \\
\hline Negative affect & 30.691 & 7.125 & \\
\hline Affective Well-being Index & 0.098 & 1.620 & \\
\hline \multicolumn{4}{|l|}{ Cognitive well-being (in 2001) } \\
\hline Life satisfaction & 4.063 & 0.758 & \\
\hline Social support & 50.678 & 9.246 & \\
\hline Subjective health & 3.955 & 0.791 & \\
\hline Optimism & 20.404 & 3.750 & \\
\hline Cognitive Well-being Index & 0.058 & 0.669 & \\
\hline \multicolumn{4}{|l|}{ Sociodemographic factors } \\
\hline \multicolumn{4}{|l|}{ Gender } \\
\hline Female & & & $748(56.2)$ \\
\hline Male & & & $584(43.8)$ \\
\hline Age (in 2001) & 31.691 & 4.992 & \\
\hline \multicolumn{4}{|l|}{ Occupational status } \\
\hline Manual & & & $427(32.1)$ \\
\hline Lower grade non-manual & & & $251(18.8)$ \\
\hline Upper grade non-manual & & & $654(49.1)$ \\
\hline \multicolumn{4}{|l|}{ Educational level } \\
\hline Comprehensive school & & & $432(32.4)$ \\
\hline High school or occupational school & & & $637(47.8)$ \\
\hline Academic level & & & $263(19.7)$ \\
\hline \multicolumn{4}{|l|}{ Parental occupational status } \\
\hline Manual & & & $506(38.0)$ \\
\hline Lower grade non-manual & & & $585(43.9)$ \\
\hline Upper grade non-manual & & & $241(18.1)$ \\
\hline \multicolumn{4}{|l|}{ Parental educational level } \\
\hline Comprehensive school & & & $422(31.7)$ \\
\hline High school or occupational school & & & $568(42.6)$ \\
\hline Academic level & & & $342(25.7)$ \\
\hline
\end{tabular}


Table 2. Results of linear regression analyses on cross-sectional associations of affective and cognitive well-being with dispositional compassion in 2001. Estimates with 95\% confidence intervals (CI) of dispositional compassion.

\begin{tabular}{|c|c|c|}
\hline & $\mathrm{B}$ & $95 \% \mathrm{CI}$ \\
\hline \multicolumn{3}{|l|}{ Affective well-being } \\
\hline Positive affect & $0.221 * * *$ & $0.169 ; 0.274$ \\
\hline Negative affect & $-0.358 * * *$ & $-0.406 ;-0.309$ \\
\hline The Affective Well-being Index & $0.345^{* * *}$ & $0.295 ; 0.396$ \\
\hline \multicolumn{3}{|l|}{ Cognitive well-being } \\
\hline Life satisfaction & $0.149 * * *$ & $0.094 ; 0.203$ \\
\hline Social support & $0.194 * * *$ & $0.142 ; 0.246$ \\
\hline Subjective health & $0.094 * *$ & $0.040 ; 0.148$ \\
\hline Optimism & $0.307 * * *$ & $0.256 ; 0.357$ \\
\hline The Cognitive Well-being Index & $0.265 * * *$ & $0.213 ; 0.317$ \\
\hline
\end{tabular}

The analyses were adjusted for age, gender, and socioeconomic status in childhood and adulthood.

Note: Compassion was standardized to mean $=0$ and $\mathrm{SD}=1$. Hence, $\mathrm{B}$ refers to change in each indicator of well-being per one-unit change (i.e. 1-SD change) in compassion. 
Table 3. The goodness-of-fit statistics for the cross-lagged models on the predictive relationships of dispositional compassion with positive affect, negative affect, and social support.

\begin{tabular}{llllllllll}
\hline & & & & & & & \multicolumn{3}{c}{ Model comparisons } \\
\cline { 6 - 9 } & $\chi^{2}$ value & $d f$ & $p$ & RMSEA & CFI & BIC & $\chi^{2}$ difference test & $d f$ & $p$ \\
\hline Model 1 & 262.145 & 40 & $<.001$ & .057 & .958 & 66546.589 & & & \\
Model 2 & 212.595 & 34 & $<.001$ & .056 & .966 & 66541.666 & $\chi^{2}(2$ vs. 1)=49.550 & 6 & $<.001$ \\
Model 3 & 251.536 & 34 & $<.001$ & .061 & .959 & 66580.607 & $\chi^{2}(3$ vs. 1)=10.609 & 6 & .101 \\
Model 4 & 202.144 & 28 & $<.001$ & .061 & .967 & 66575.842 & $\chi^{2}(4$ vs. 1)=60.001 & 12 & $<.001$ \\
& & & & & & & $\chi^{2}(4$ vs. 2)=10.451 & 6 & .107 \\
& & & & & & & $\chi^{2}(4$ vs. 3)=49.392 & 6 & $<.001$ \\
\hline
\end{tabular}

RMSEA $=$ the Root Mean Square Error of Approximation. CFI $=$ the Comparative Fit Index. BIC $=$ the Bayesian Information Criterion. $N=1699$

Model 1: Autoregressive model (no cross-lagged predictive paths).

Model 2: Cross-lagged predictive paths from compassion to positive affect, negative affect and social support.

Model 3: Cross-lagged predictive paths from positive affect, negative affect, and social support to compassion.

Model 4: Cross-lagged predictive paths in both directions. 
Table 4. Results of the multilevel models. Estimates (B) with $95 \%$ confidence intervals (CI) of dispositional compassion and follow-up time, when predicting the course of the Affective Well-being Index and social support.

\begin{tabular}{|c|c|c|c|c|}
\hline & \multicolumn{2}{|c|}{ The Affective Well-being Index } & \multicolumn{2}{|c|}{ Social support } \\
\hline & $\mathrm{B}$ & $(95 \% \mathrm{CI})$ & $\mathrm{B}$ & $(95 \% \mathrm{CI})$ \\
\hline \multicolumn{5}{|l|}{ Fixed effects } \\
\hline Intercept & -0.179 & $-0.464 ; 0.107$ & $0.593 * * *$ & $0.305 ; 0.880$ \\
\hline Compassion in 1997 & $0.361 * * *$ & $0.311 ; 0.410$ & $0.230 * * *$ & $0.180 ; 0.280$ \\
\hline Follow-up time (in years) & $0.023^{*}$ & $0.005 ; 0.041$ & $0.039 * * *$ & $0.018 ; 0.060$ \\
\hline Follow-up time squared & $-0.001 *$ & $-0.002 ;-0.000$ & -0.002 & $-0.003 ; 0.000$ \\
\hline $\begin{array}{r}\text { Compassion in 1997* } \\
\text { Follow-up time }\end{array}$ & $-0.009 * * *$ & $-0.013 ;-0.005$ & $-0.006^{*}$ & $-0.012 ;-0.001$ \\
\hline \multicolumn{5}{|l|}{ Random effects } \\
\hline Variance of intercept & $0.760^{*}$ & $0.718 ; 0.804$ & $0.732 *$ & $0.688 ; 0.780$ \\
\hline Variance of follow-up time & $0.052 *$ & $0.048 ; 0.058$ & $0.049^{*}$ & $0.040 ; 0.060$ \\
\hline Residual variance & $0.562 *$ & $0.538 ; 0.587$ & $0.591 *$ & $0.566 ; 0.617$ \\
\hline
\end{tabular}

$* * * p<.001 * * p<.01 * p<.05 N=1312$

Note: All the models were adjusted for age, gender and socioeconomic factors in childhood and adulthood. The total follow-up time was 15 years for the Affective Well-being Index and 10 years for social support. Compassion was standardized to mean $=0$ and $\mathrm{SD}=1$. Hence, B refers to change in each indicator of well-being per one-unit change (i.e. 1-SD change) in compassion. 


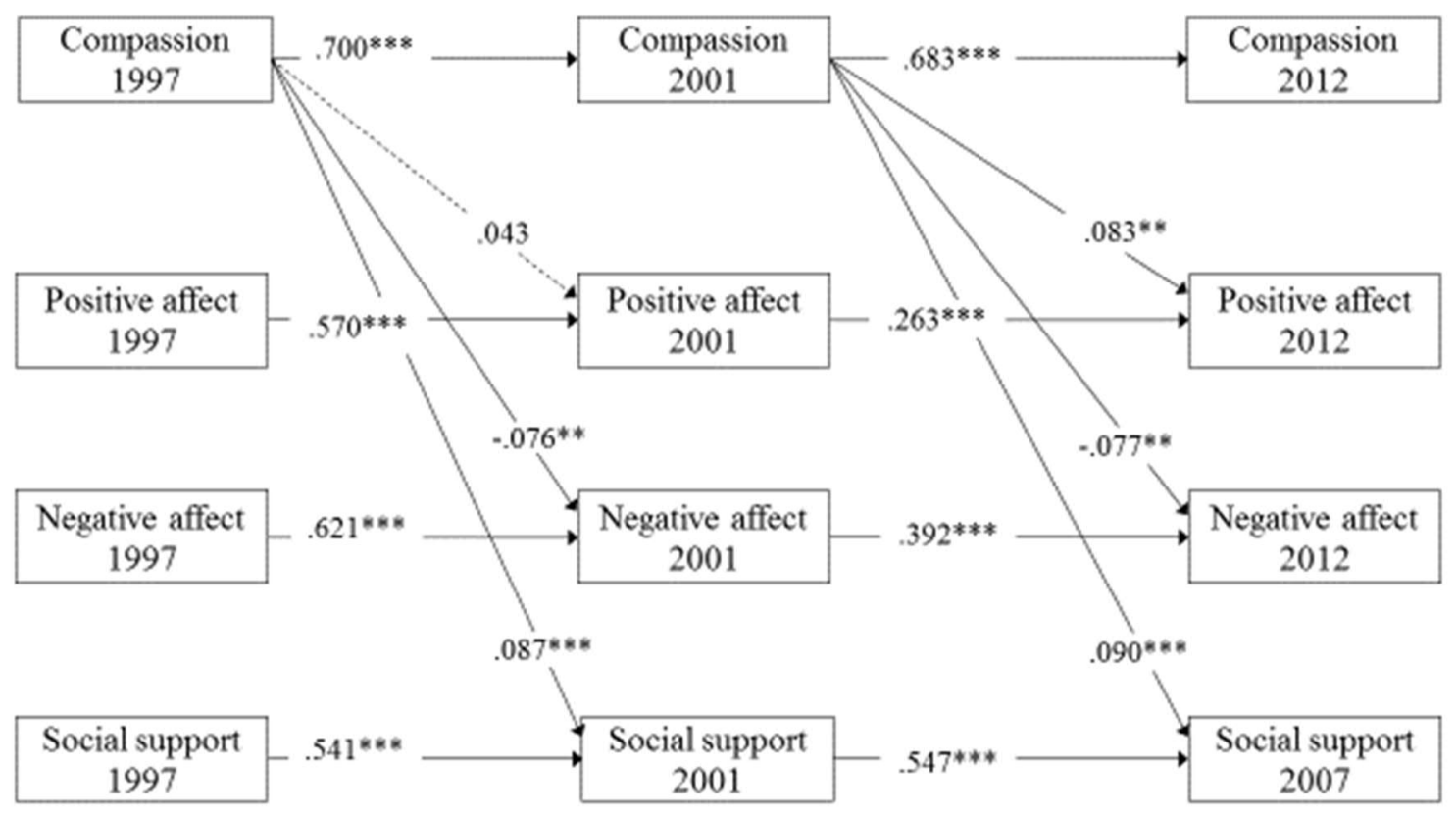

Figure 1. Standardized regression paths of the model 2 (i.e. stability coefficients and the cross-lagged paths from compassion to positive affect, negative affect, and social support at three measurement points). Note: Control variables and covariances between variables at each timepoint are omitted from the figure. $* * * p<.001 * * p<.01 N=1699$ 
(a)

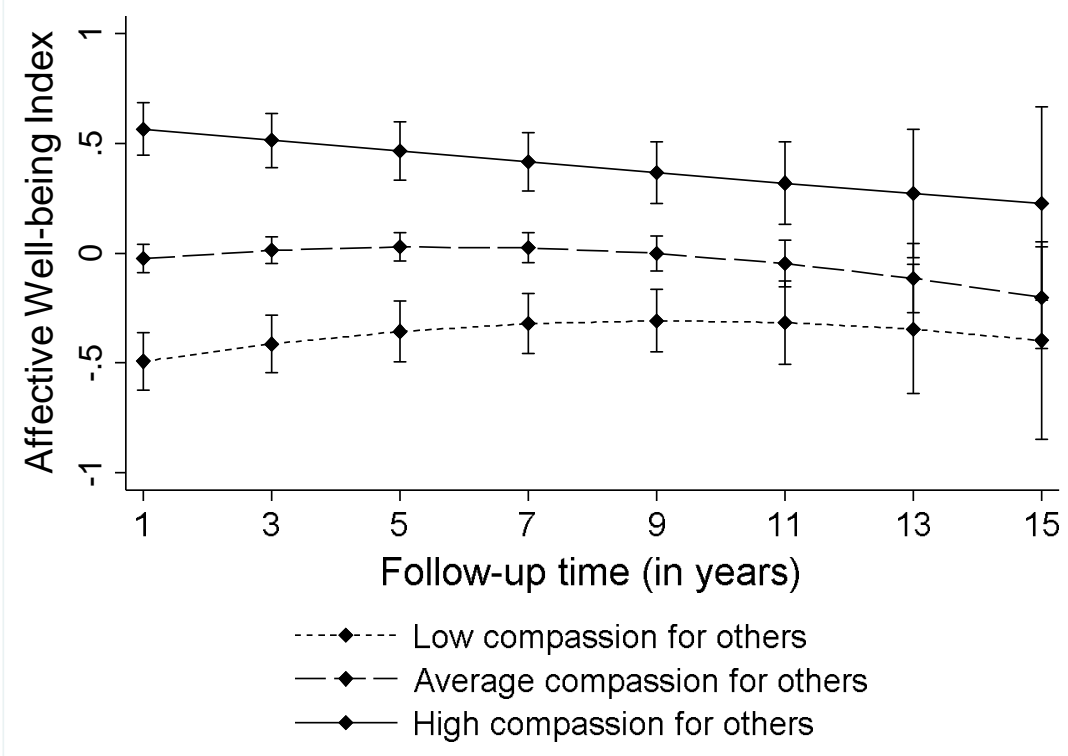

(b)

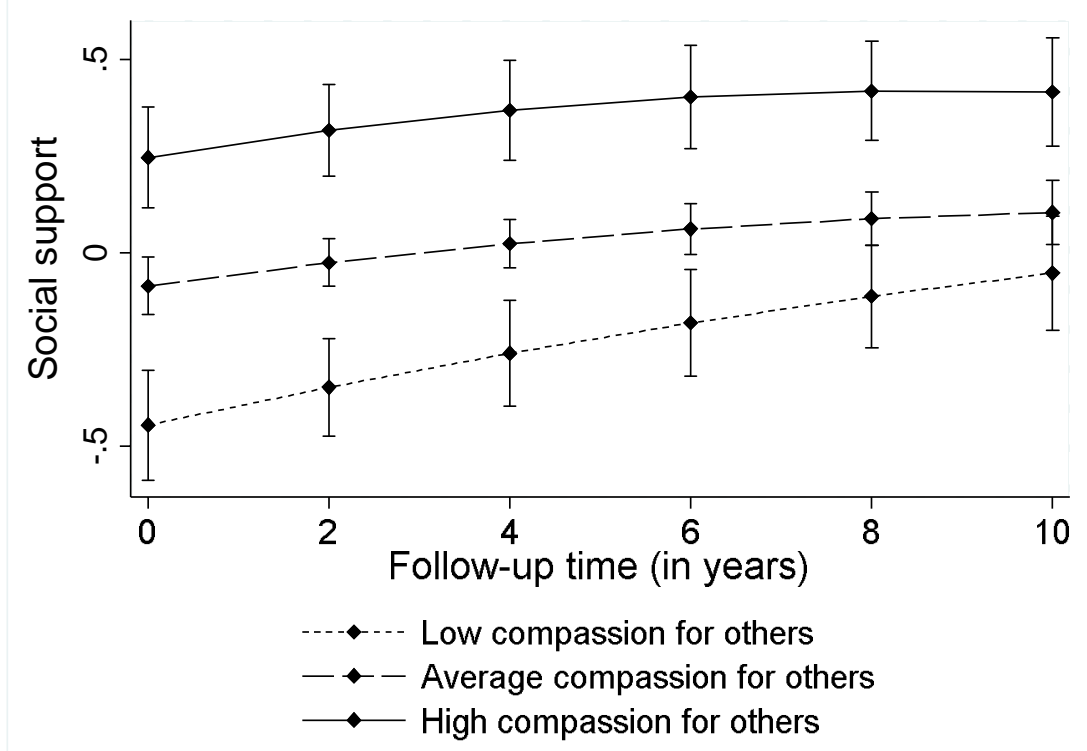

Figure 2. Growth trajectories for the standardized scores of (a) the Affective Well-being Index and (b) social support over the follow-up separately for subjects belonging to low (-1 SD), average, and high (+1 SD) in compassion in 1997. Predicted means with 95\% confidence intervals. 
Supplementary Table 1. The measurement years of the study variables.

\begin{tabular}{|c|c|c|c|c|c|}
\hline & 1980 & 1997 & 2001 & 2007 & 2012 \\
\hline Compassion & & $\mathrm{X}$ & $\mathrm{X}$ & & $\mathrm{X}$ \\
\hline \multicolumn{6}{|l|}{ Affective well-being } \\
\hline Positive affect & & $X$ & $X$ & & $\mathrm{X}$ \\
\hline Negative affect & & $\mathrm{X}$ & $X$ & & $\mathrm{X}$ \\
\hline \multicolumn{6}{|l|}{ Cognitive well-being } \\
\hline Social support & & $\mathrm{X}$ & $\mathrm{X}$ & $\mathrm{X}$ & \\
\hline Life satisfaction & & $\mathrm{X}$ & & & \\
\hline Subjective health & & $\mathrm{X}$ & & & \\
\hline Socioeconomic factors in childhood & $\mathrm{X}$ & & & & \\
\hline Socioeconomic factors in adulthood & & & & $\mathrm{X}$ & \\
\hline
\end{tabular}


Supplementary Table 2. The fully descripted results of linear regression analyses on cross-sectional associations of dispositional compassion with affective well-being in 2001. Estimates with 95\% confidence intervals (CI) of dispositional compassion.

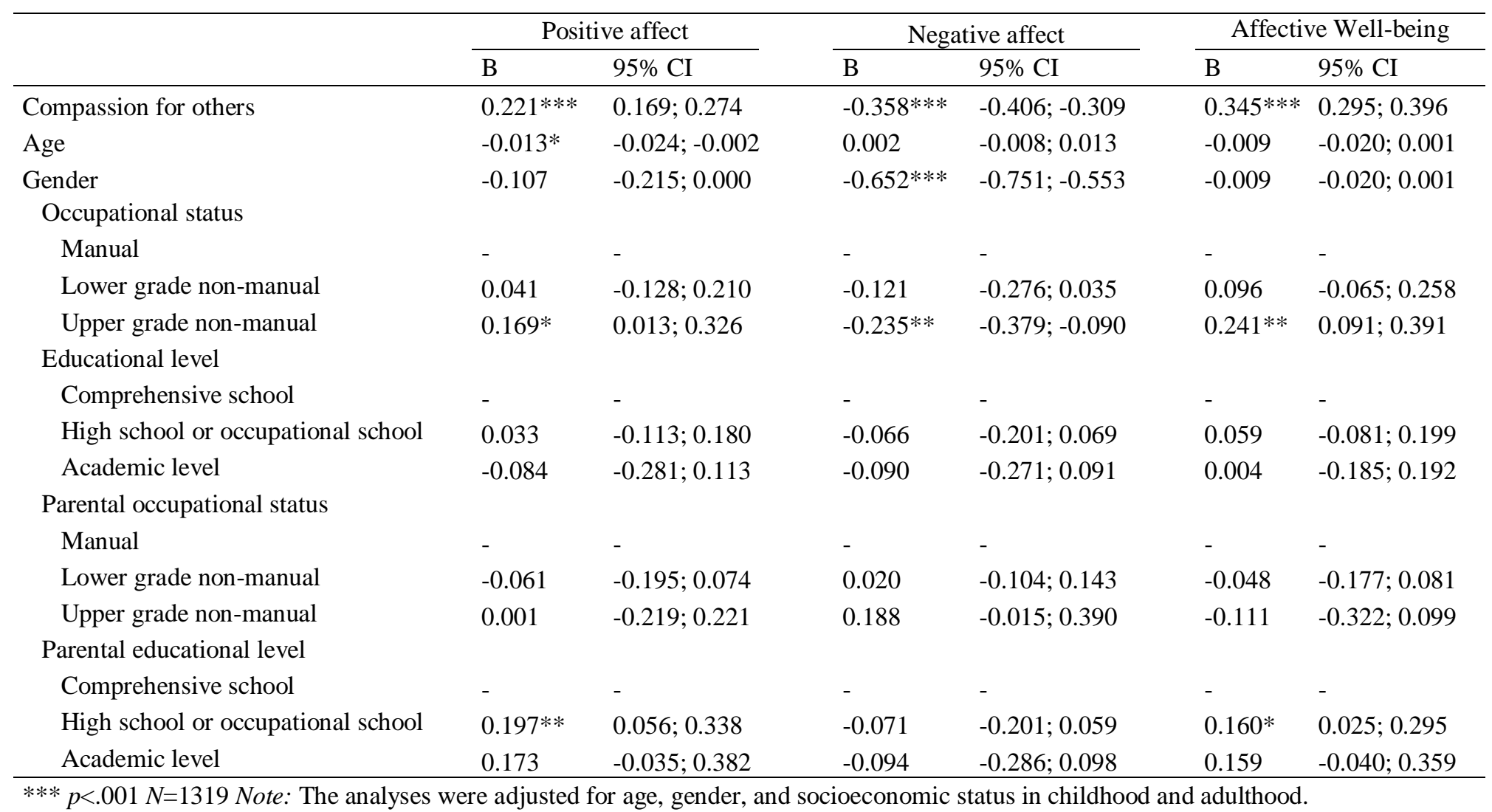


Supplementary Table 3. The fully descripted results of linear regression analyses on cross-sectional associations of dispositional compassion with cognitive well-being in 2001. Estimates with 95\% confidence intervals (CI) of dispositional compassion.

\begin{tabular}{|c|c|c|c|c|c|c|c|c|c|c|}
\hline & \multicolumn{2}{|c|}{ Life satisfaction } & \multicolumn{2}{|c|}{ Social support } & \multicolumn{2}{|c|}{ Subjective health } & \multicolumn{2}{|c|}{ Optimism } & \multicolumn{2}{|c|}{ Cognitive Well-being Index } \\
\hline & $\mathrm{B}$ & $95 \% \mathrm{CI}$ & $\mathrm{B}$ & $95 \% \mathrm{CI}$ & $\mathrm{B}$ & $95 \% \mathrm{CI}$ & $\mathrm{B}$ & $95 \% \mathrm{CI}$ & $\mathrm{B}$ & $95 \% \mathrm{CI}$ \\
\hline Compassion for others & $0.149 * * *$ & $0.094 ; 0.203$ & $0.194 * * *$ & $0.142 ; 0.246$ & $0.094 * *$ & $0.040 ; 0.148$ & $0.307 * * *$ & $0.256 ; 0.357$ & $0.265 * * *$ & $0.213 ; 0.317$ \\
\hline Age & 0.005 & $-0.005 ; 0.017$ & $-0.025 * * *$ & $-0.036 ;-0.015$ & $-0.014 *$ & $-0.025 ;-0.002$ & 0.005 & $-0.006 ; 0.015$ & -0.010 & $-0.021 ; 0.001$ \\
\hline Gender & 0.046 & $-0.065 ; 0.156$ & $-0.394 * * *$ & $-0.499 ;-0.289$ & 0.093 & $-0.017 ; 0.204$ & $0.108 *$ & $0.005 ; 0.210$ & -0.052 & $-0.158 ; 0.053$ \\
\hline \multicolumn{11}{|l|}{ Occupational status } \\
\hline Manual & - & - & - & - & - & - & & & & \\
\hline Lower grade non-manual & -0.121 & $-0.294 ; 0.052$ & 0.044 & $-0.141 ; 0.145$ & 0.123 & $-0.050 ; 0.297$ & 0.136 & $-0.025 ; 0.297$ & 0.065 & $-0.101 ; 0.230$ \\
\hline Upper grade non-manual & 0.054 & $-0.106 ; 0.215$ & $0.184 *$ & $0.031 ; 0.337$ & $0.209 *$ & $0.048 ; 0.370$ & $0.298 * * *$ & $0.148 ; 0.448$ & $0.265 * *$ & $0.112 ; 0.419$ \\
\hline \multicolumn{11}{|l|}{ Educational level } \\
\hline Comprehensive school & - & - & - & - & - & - & & & & \\
\hline $\begin{array}{l}\text { High school or } \\
\text { occupational school }\end{array}$ & 0.041 & $-0.109 ; 0.191$ & 0.002 & $-0.141 ; 0.145$ & 0.041 & $-0.109 ; 0.191$ & 0.094 & $-0.046 ; 0.234$ & 0.063 & $-0.080 ; 0.206$ \\
\hline Academic level & 0.044 & $-0.158 ; 0.246$ & -0.002 & $-0.194 ; 0.191$ & 0.001 & $-0.200 ; 0.203$ & $0.235 *$ & $0.047 ; 0.423$ & 0.099 & $-0.094 ; 0.292$ \\
\hline \multicolumn{11}{|c|}{ Parental occupational status } \\
\hline Manual & - & - & - & - & - & - & & & & \\
\hline Lower grade non-manual & 0.010 & $-0.128 ; 0.147$ & $0.138^{*}$ & $0.007 ; 0.269$ & -0.068 & $-0.205 ; 0.070$ & $0.135^{*}$ & $0.006 ; 0.263$ & 0.076 & $-0.055 ; 0.208$ \\
\hline Upper grade non-manual & 0.063 & $-0.162 ; 0.288$ & 0.183 & $-0.031 ; 0.397$ & -0.180 & $-0.405 ; 0.046$ & 0.195 & $-0.015 ; 0.404$ & 0.093 & $-0.122 ; 0.308$ \\
\hline \multicolumn{11}{|l|}{ Parental educational level } \\
\hline Comprehensive school & - & - & - & - & - & - & & & & \\
\hline $\begin{array}{l}\text { High school or } \\
\text { occupational school }\end{array}$ & 0.056 & $-0.088 ; 0.201$ & 0.040 & $-0.097 ; 0.178$ & 0.138 & $-0.006 ; 0.282$ & 0.074 & $-0.061 ; 0.208$ & 0.110 & $-0.028 ; 0.248$ \\
\hline Academic level & 0.014 & $-0.200 ; 0.228$ & -0.031 & $-0.235 ; 0.172$ & $0.241 *$ & $0.027 ; 0.454$ & 0.074 & $-0.125 ; 0.273$ & 0.106 & $-0.098 ; 0.310$ \\
\hline
\end{tabular}


Supplementary Figure 1. The results of the confirmatory factor analysis regarding the Compassion Scale. Note: The error terms of reversely-scaled items were allowed to correlate with each other, and the error terms of positively-scaled items were allowed to correlate with each other. The covariances between the error terms were omitted from the figure for clarity.

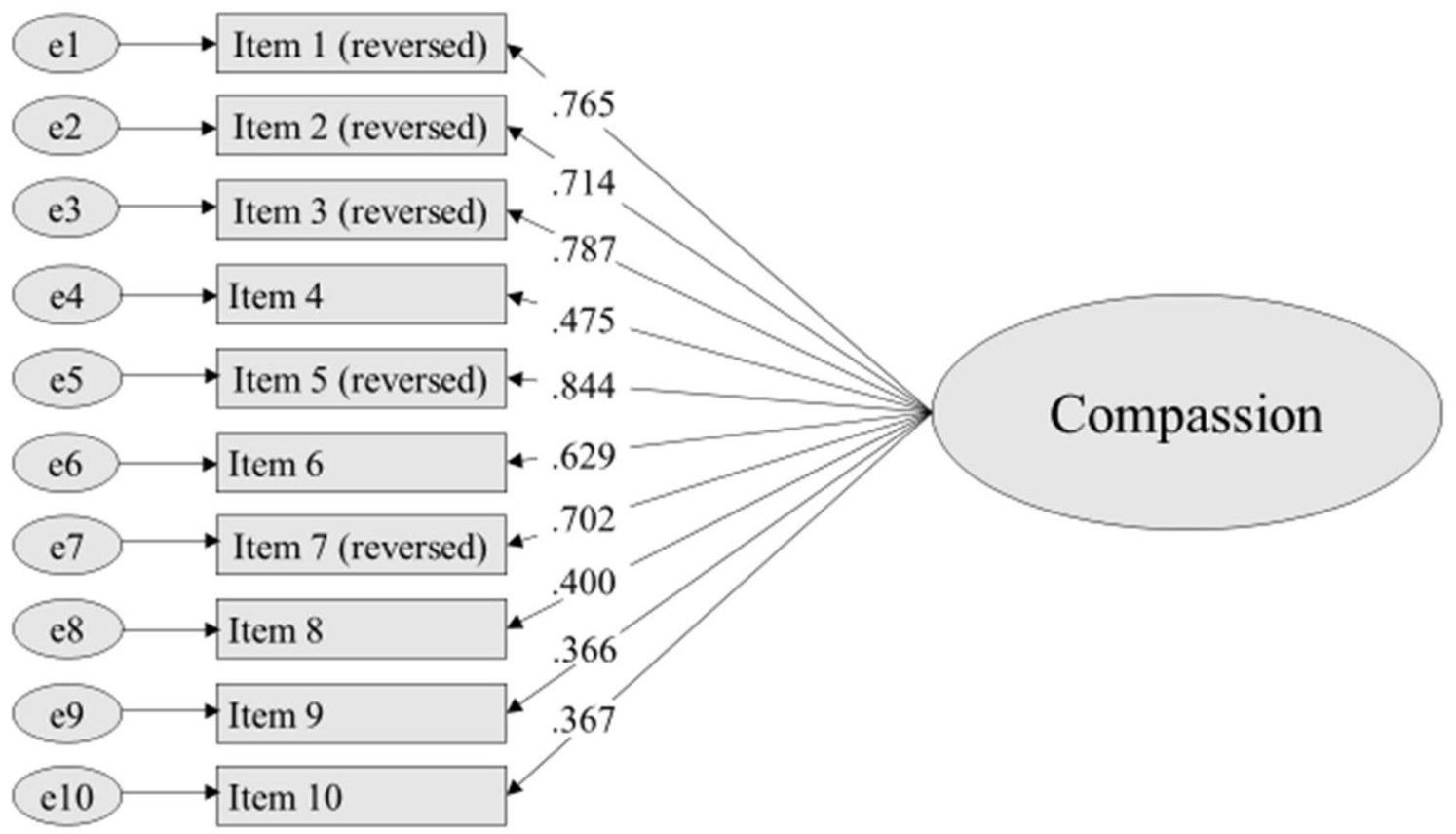

\begin{tabular}{ll}
\hline Goodness-of-fit indices & Proposed model \\
\hline$\chi^{2}(\mathrm{df})$ & $74.244(15)^{* * * *}$ \\
CFI & 0.993 \\
RMSEA & 0.044 \\
BIC & 50967.582 \\
\hline$* * * p<.001$ & \\
RMSEA = the Root Mean Square Error of Approximation. \\
CFI = the Comparative Fit Index. \\
BIC $=$ the Bayesian Information Criterion.
\end{tabular}

